\title{
Combined Use of Multiple Drought Indices for Global Assessment of Dry Gets Drier and Wet Gets Wetter Paradigm ${ }^{\circ}$
}

\author{
TAO YANG \\ Key Laboratory of Alpine Ecology, Institute of Tibetan Plateau Research, Chinese Academy of Sciences, \\ and University of Chinese Academy of Sciences, Beijing, China \\ JiNZHi Ding, DAN LIU, AND XIAOYI WANG \\ Key Laboratory of Alpine Ecology, Institute of Tibetan Plateau Research, \\ Chinese Academy of Sciences, Beijing, China \\ TAO WANG \\ Key Laboratory of Alpine Ecology, Institute of Tibetan Plateau Research, Chinese Academy of Sciences, \\ and CAS Center for Excellence in Tibetan Plateau Earth Sciences, Chinese Academy of Sciences, \\ Beijing, and School of Life Sciences, Lanzhou University, Lanzhou, China
}

(Manuscript received 1 May 2018, in final form 26 October 2018)

\begin{abstract}
Global warming is expected to enhance the global hydrological cycle, leading dry regions to become drier and wet regions to become wetter (the DDWW paradigm). However, this hypothesis has been challenged by both observational and modeling studies. One major source of these disagreements originates from the choice of the drought indices used. Hydrological processes are complex, but drought indices are often based on a relatively simple calculation. A single index may, therefore, place undue emphasis on particular processes while ignoring others, with the result that it would not capture the holistic picture of hydrological changes and may even lead to an incorrect interpretation. Six common drought indices were calculated for the global vegetated land areas for the period from 1982 to 2012 and different indices tend to create apparently contradictory results for many regions. To overcome the single-index problem, the six drought indices were integrated into a composite map of global land moisture trends. By using this integrated approach, the majority $(55 \%)$ of vegetated land areas experienced wetting or drying trends. For the regions with significant changes, supporting evidence was identified for the DDWW paradigm in one-fifth of the area. The opposite pattern to DDWW (dry areas becoming wetter and wet areas drier) occurred over $29 \%$ of the area. We also find an asymmetrical pattern with a larger proportion of wet areas getting wetter (12\%) than dry areas getting drier ( $8 \%$ ). The DDWW theory is more useful when the pure precipitation-driven drought metrics are considered but when evapotranspiration and soil conditions are integrated, the DDWW is not conclusive.
\end{abstract}

\section{Introduction}

The hydrological cycle is a key component of the Earth system, affecting the atmosphere, biosphere, lithosphere, and anthroposphere (Hoekstra and Mekonnen

Supplemental information related to this paper is available at the Journals Online website: https://doi.org/10.1175/ JCLI-D-18-0261.s1.

Corresponding author: Jinzhi Ding, jzding@itpcas.ac.cn; Tao Wang, twang@itpcas.ac.cn
2012; Seneviratne et al. 2010). As the climate warms, there are projected to be significant changes in dryness and wetness of the land surface in many regions. These changes will have major impacts on societies, economies, and ecosystems throughout the world (Dai 2011; Piao et al. 2010; Thornton et al. 2014). For instance, severe drought can lead to yield reductions and reproductive failure in many crops, increased occurrence of fires, and outbreaks of diseases (Thornton et al. 2014). Drought causes an average of $\$ 6-\$ 8$ billion (U.S. dollars) per year in damages over the United States (Dai 2011). Research into assessing past changes of hydrological conditions 
and improving their prediction is essential for both policy-makers and the public to help to mitigate the widespread, damaging consequences of changes in dryness or wetness on the socioeconomic system.

Temporal trends of dryness and wetness are the subject of a growing body of studies at both regional (Briffa et al. 2009; Chou et al. 2009; Sheffield et al. 2004) and global scales (Dai 2011; Feng and Zhang 2015; Greve et al. 2014; Huang et al. 2016; Kumar et al. 2015; Sheffield et al.2012). The paradigm widely used to summarize the expected trends of the global hydrological cycle is that dry regions tend to get drier, and wet regions tend to get wetter (DDWW; Chou et al. 2009; Feng and Zhang 2015; Held and Soden 2006; Liu and Allan 2013; Seager and Vecchi 2010). The paradigm refers to two competing variables: precipitation $(P)$ and evapotranspiration (ET). Global warming increases the amount of water vapor in the atmosphere, resulting in an enhanced water balance ( $P-\mathrm{ET}$ ) over humid regions (convergence zones) and reduced $P$ - ET over arid regions (divergence zones; Liu and Allan 2013; Kumar et al. 2015; Lu et al. 2018). However, the paradigm has been questioned by both observational and modeling studies (Sheffield et al. 2012; Greve et al. 2014). For instance, studies based on the Palmer drought severity index (PDSI; Briffa et al. 2009; Dai 2011) show that drought increased in frequency and severity between the 1970s and the early twenty-first century. On the contrary, another study based on the balance of potential evaporation and soil water (Sheffield et al. 2012) detected little change in global drought. Subsequently, Greve et al. (2014) found that only $10.8 \%$ of the global land area shows a robust "dry gets drier, wet gets wetter" pattern over the past 60 years. In addition to these conflicting results obtained from observations of global land drought, large differences also exist between studies based on the observed (Chou et al. 2009; Dai 2011) and model-simulated (Burke and Brown 2008) drought datasets. Considering all these results, it is clear that there are still major uncertainties regarding dryness or wetness trends for both the past and the future (Trenberth et al. 2014).

The major uncertainties partly originate from the choice of dataset, especially the precipitation data used (Greve et al. 2014; Trenberth et al. 2014) and the significant internal variability of these datasets (Kumar et al. 2015). Importantly, different drought indices emphasize different aspects of the water balance, which may help to explain the discrepancies between different studies even when they are based on the same climate datasets. For example, the widely used standard precipitation index (SPI) is calculated solely from precipitation records and represents the water supply conditions over the study regions of interest (McKee et al. 1993). In contrast, the PDSI, the standardized precipitation evapotranspiration index (SPEI; VicenteSerrano et al. 2010), and the aridity index (AI; Huang et al. 2016), also among the most used drought indices, assess both precipitation inputs and the water demand from the atmosphere, although the latter two indices do not take land surface conditions into consideration. Other drought indices, such as the standardized soil moisture index (SSI), and the standardized evapotranspiration index (SETI) are based on measures of soil moisture and ET (Quiring and Ganesh 2010), separately. These indices have been widely used to analyze drought trends in the context of climate change, but most studies, with only a few exceptions, were solely based on one index (Dai 2011; Feng and Zhang 2015; Greve et al. 2014; Huang et al. 2016). To obtain a holistic picture of hydrological change over the global land surface, an assessment of drought trends, made by integrating the various aspects of the water balance, as represented by a variety of different drought indices, is urgently required.

Here, we synthesized a dataset of six commonly used drought indices for the global vegetation-covered land areas. The dataset was used to qualitatively assess the trends of drought over these areas for the period 19822012. An innovative output from this study is a composite assessment of global drought trends based on the six drought indices, representing a systematic consideration of precipitation, evapotranspiration, soil moisture, and land-cover information. The map of dryness or wetness trends, created from this composite assessment, is used to test the DDWW paradigm.

\section{Data and methods}

\section{a. Drought indices}

We consider a pure $P$-driven index (SPI), a pure ETdriven index (SETI), and mixed-driven indices (SPEI, AI, PDSI, and SSI). SPI is solely calculated from precipitation data. Precipitation is normalized using a probability distribution so that the values of SPI can be interpreted as the number of standard deviations that the cumulative precipitation at a given time scale (e.g., 6 months and 1 year) deviates from the long-term mean. The probabilistic nature of the index means it is comparable across time and space (Mishra and Singh 2011). However, it should be noted that the values of SPI could be sensitive to the choice of the length of the precipitation record. Although SPI is commonly acknowledged to characterize meteorological drought, the use of SPI calculated at different time scales (from 1 month up to 2 years) allows us to assess the effects of precipitation on different water-resource components such as soil 
moisture and streamflow (Vicente-Serrano et al. 2010). Here, we use SPI from the National Centers for Environmental Prediction (NCEP) and the National Center for Atmospheric Research (NCAR) reanalysis project at a spatial resolution of $1^{\circ}$ for the period 1982-2012 (https://rda.ucar.edu), which is calculated using an improved version of the University of East Anglia Climatic Research Unit (CRU) precipitation dataset (TS3.21). We select 12-month SPI, which represents the yearly deviation of precipitation from the mean and is suggested to reflect the impacts of drought on the hydrological regimes and water resources of a region (Vicente-Serrano 2006).

SPEI takes the effects on drought of both precipitation and temperature into account, in contrast to SPI, which is based only on precipitation data, by calculating the difference between precipitation and reference evapotranspiration $\left(\mathrm{ET}_{0}\right)$, to represent the climatic water balance. The $\mathrm{ET}_{0}$ is computed by using the PenmanMonteith method, which is a physically based approach consisting of a function of radiation, temperature, humidity, and wind speed (Allen et al. 1998). The comparison of SPI with SPEI should provide insights into the possible influences of warming (and also changes in wind speed and radiation) on changes in droughts. Similarly to SPI, SPEI has multiple temporal scales that could be used to reflect the effect of droughts on various components of the hydrological system (Vicente-Serrano et al. 2010). In this study, we used 12-month SPEI, based on CRU TS3.0 data (http://digital.csic.es), with a spatial resolution of $0.5^{\circ}$, to assess the trends of global hydroclimate changes.

$\mathrm{AI}$, the ratio of precipitation to potential evapotranspiration (PET), also represents a balance between the moisture supply (precipitation) and demand (Feng and Fu 2013; Berg and Sheffield 2018). Here, we compute AI by using the 6-hourly precipitation data from version 6.1 of the CRU-NCEP product (https://www. earthsystemgrid.org), with a spatial resolution of $0.5^{\circ}$. PET was derived from the Global Land Evaporation Amsterdam Model (GLEAM) dataset, version 3.0a (Martens et al. 2017; Miralles et al. 2011), with a spatial resolution of $0.25^{\circ}$ (http://www.gleam.eu). We also use the well-established definition of wet or dry regions at the land surface based on AI (UNEP 1992; Greve et al. 2014; Huang et al. 2016) for the assessment of the DDWW paradigm, rather than the value of $P-\mathrm{ET}$, which was used in the original ocean-centric formulation of the DDWW, but is not applicable to land areas.

The PDSI (Palmer 1965) is one of the most widely used drought indices. The heart of the PDSI algorithm relies on a simple water-balance model, which is equal to the sum of precipitation, ET, runoff, and changes in soil moisture storage. The computation of soil moisture storage relies on a two-layer "bucket" model, in which the total soil-water-holding capacity, parameterized as a function of soil texture and soil depth, is location dependent, with the top layer assumed to hold $25.4 \mathrm{~mm}$ of water and the bottom soil layer having the remaining water capacity (Dai et al. 2004). All of the basic terms in this simple water-balance model can be determined using precipitation, temperature, and the local soil-water characteristics as inputs. As with SPEI, the effect of temperature on drought is incorporated via the $\mathrm{ET}_{0}$ term and the actual evapotranspiration. It has been demonstrated that the computation of PDSI is sensitive to the method of calculating $\mathrm{ET}_{0}$ (Sheffield et al. 2012). Although PDSI was initially developed as an agricultural monitoring tool in the United States in the 1960s (Palmer 1965), it has frequently been adopted to represent meteorological and hydrological drought (e.g., Dai et al. 2004). PDSI is only considered on the annual time scale in this study because of inherent limitations in the algorithm (Alley 1984; Yilmaz et al. 2016). This restriction might partly alleviate the related issues that the PDSI algorithm makes no allowance for the effect of snowmelt or frozen soils and fails to account for the natural lag between moisture surplus and streamflow. Here, we use self-calibrating PDSI calculated with Penman-Monteith based PET (sc_PDSI_pm), which is widely recognized as an improvement on the original PDSI (Dai 2011). The spatial resolution is $2.5^{\circ} \times 2.5^{\circ}$ and the climate data are for the period 1982-2012 (http:// www.cgd.ucar.edu).

PDSI has been used in the past to indicate soil moisture drought since the necessary quantity and quality of soil moisture observations has not been available. However, because of the continued improvement in satellite soil moisture retrieval and the development of model data assimilation techniques (Reichle et al. 2004), long-term satellite-based soil moisture data have reached a level of quality that enables us to calculate drought indices related to soil moisture (SSI). To be more comparable with SPI and SPEI, we calculated annual means of SSI using monthly root-zone soil moisture data from the version 3.0a of the GLEAM dataset (Martens et al. 2017; Miralles et al. 2011), at a spatial resolution of $0.25^{\circ}$ (http://www.gleam.eu). Note the GLEAM soil moisture is only representative of the top surface soil moisture conditions (Berg and Sheffield 2018; Martens et al. 2017).

ET is the sum of evaporation and plant transpiration, reflecting the atmospheric water demand (Jensen et al. 1990), which is an important part of the water cycle (Berg and Sheffield 2018; Swann et al. 2016). Here, ET data are obtained from the version 3.0a of the GLEAM 
dataset with a spatial resolution of $0.25^{\circ}$ (http://www. gleam.eu). Both SSI and SETI are derived by fitting an empirical (or nonparametric) distribution function to soil moisture and ET data. Therefore, an advantage of these two indices over SPI and SPEI is that we do not need to assume the existence of a suitable parametric probability distribution function (Farahmand and Aghakouchak 2015). In addition, all the drought indices used are in the vegetation-covered area over land based on the annual mean of monthly NDVI, with the exclusion of potential bias from snow-covered areas and seasons (monthly NDVI records less than 0) and from uncovered and sparsely vegetated areas (annual mean NDVI less than 0.1; Wang et al. 2017). The NDVI data used are derived from the third-generation NDVI from AVHRR sensors of the Global Inventory Modeling and Mapping Studies [GIMMS (NDVI3g)] dataset (https:// ecocast.arc.nasa.gov) with a horizontal resolution of $0.083^{\circ}$ for every 15 -day interval.

\section{b. Analyses}

The drying or wetting trends were estimated from the slope of the linear regression with a nonparametric Mann-Kendall test (Mann 1945; Kendall 1975; Gilbert 1988), which can be used to determine whether the estimated slope of the linear regression line is different from zero at the $P \leq 0.05$ level. We also assessed changes in the global drought area over the past decades. For this assessment, the drought areas are defined as areas where each drought index is below the value of the 20th percentile for the period 1982-2012 (Zhao and Dai 2015; Peñuelas et al. 2017).

The sign of the trends in the different drought indices were divided into three classes: wetting significantly $(+)$, drying significantly $(-)$, or no significant changes $(0)$, at the 0.05 significance level. We generated a composite map of the level of certainty in global drying or wetting at a spatial resolution of $1^{\circ}$, based on the results of the six drought indices. The level of certainty was defined as follows: "very likely" when the sign of the trend in dryness or wetness was matched by five or six drought indices (5-6 "+" or "- ", and 0-1 " 0 "), "likely" if the sign of the trend in dryness or wetness was matched by three or four drought indices (3-4 "+" or " -", and 2-3 " 0 "), "probably" if the sign of the trend in dryness or wetness was matched by one or two drought indices (1-2 "+" or "-", and the rest are " 0 "); "uncertain" when inconsistent trends were found among different indices (both "+" or "-" exist) or no significant changes for all of the six indices were detected (all indices were " 0 "). To investigate the DDWW paradigm, the distribution of arid, humid, and transitional areas was also required. We defined these areas by using the ratio between precipitation and PET, known as the AI, for the period from 1982 to 2012. Regions with $\mathrm{AI} \leq 0.5$ were classified as arid, while regions with $\mathrm{AI} \geq$ 0.65 were classified as humid. Transitional regions were defined as those where $0.50<\mathrm{AI}<0.65$ (UNEP 1992; Hulme et al. 1992).

\section{Results}

\section{a. Global drought trends and spatial patterns}

The spatial distribution of trends in these indices shows a mixture of drying and wetting. The overall statistics indicate that for SPI approximately $23.3 \%$ of vegetation-covered land area experienced significant changes in the hydrological conditions. The corresponding figures for the other indices were $22.0 \%$ for SPEI, $16.7 \%$ for AI, $24.9 \%$ for PDSI, $30.9 \%$ for SSI, and $76.0 \%$ for SETI (Fig. 1, left column). For the regions with significant changes, the wetting area covers approximately $17.1 \%$ of the study area for SPI, $15.5 \%$ for SPEI, $12.3 \%$ for AI, $11.2 \%$ for PDSI, $12.4 \%$ for SSI, and $24.0 \%$ for SETI; the drying area covers approximately $6.0 \%$ of the study area for SPI and SPEI, $4.4 \%$ for AI, $13.6 \%$ for PDSI, $18.4 \%$ for SSI, and $52.0 \%$ for SETI. The wetting area is found to be substantially larger than the drying area when SPI, SPEI, and AI were used. The use of PDSI, SSI, or SETI produced drying trends, which dominated the most regions with significant changes in hydrological conditions.

The SPI and SPEI show strong agreement in terms of the spatial pattern of significantly drying or significantly wetting regions (Fig. 1; Figs. S1, S2 in the online supplemental material). Significant wetting occurred in South and central Africa, the Amazon basin, and north Asia, while significant drying was observed in northwest America and southern South America. AI exhibits a similar pattern of drying or wetting, but with much less area experiencing significant changes, especially in north Asia, compared to SPI and SPEI (Fig. 1; Fig. S1). PDSI and SSI show distinct patterns compared with SPEI or AI. For example, PDSI and SSI show a significant drying tendency in southeast China, while SPEI and AI show no significant trends. The AI and SPEI results indicate significant wetting in east-central Africa, whereas the PDSI and SSI results show significant drying (Fig. 1; Fig. S1). SETI shows a significant drying tendency in most areas, except for the southwest North America and the Amazon basin (Fig. 1; Fig. S1).

Similarly, the drought area changed in complicated ways according to the indices used (Fig. 1, right column). The drought area decreased significantly from 1982 to 2012 by $4.1 \times 10^{3} \mathrm{~km}^{2} \mathrm{yr}^{-1}(P<0.01)$ for 

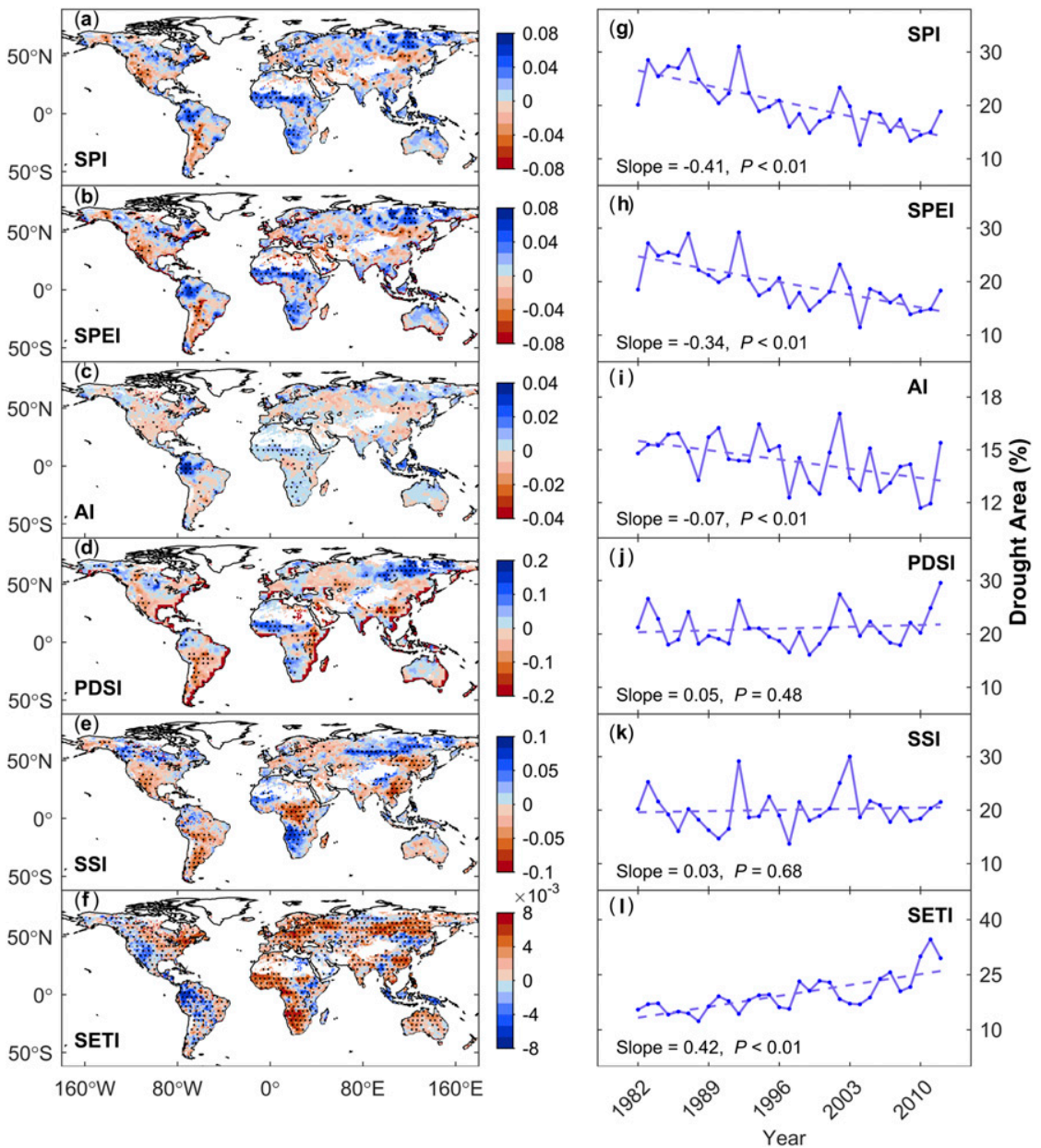

FIG. 1. Spatial distributions of the drying or wetting trends and time series of drought areas over the period 1982-2012.The drought metric includes the pure $P$-driven index (SPI), mixed $P$-ET-driven indices (SPEI, AI, PDSI, and SSI), and the pure ET-driven index (SETI). The black dots show the regions with significant trends in drought indices $(P \leq 0.05)$. The dashed lines denote the linear regression of the average drought-index series.

SPI, by $3.4 \times 10^{3} \mathrm{~km}^{2} \mathrm{yr}^{-1}(P<0.01)$ for SPEI, and by $0.7 \times 10^{3} \mathrm{~km}^{2} \mathrm{yr}^{-1}(P<0.01)$ for AI. On the contrary, the drought area increased significantly by $4.2 \times$ $10^{3} \mathrm{~km}^{2} \mathrm{yr}^{-1}(P<0.01)$ for SETI. However, there is no significant change in drought area over the study period when PDSI $(P=0.48)$ or SSI $(P=0.68)$ are considered. To summarize, we find that different drought indices create different and even conflicting results for both trends and areal coverage of drying.

\section{b. Composite assessment of global trends of dryness or wetness}

Given the substantial complexity of the hydrological system, which is related to multiple variables (e.g., precipitation, temperature, ET, runoff, and soil moisture), the use of a single variable or drought index is not appropriate to identify local changes in hydrological conditions. We overcome this problem by providing a comprehensive six-index assessment of global trends of drying or wetting (Fig. 2). The composite analysis reveals that the proportion of drying regions (circa 38.7\%) is larger than that of wetting regions (circa 16.3\%). The areas with changes toward drying conditions with confidence levels of very likely, likely, and probably cover $0.5 \%, 3.8 \%$, and $34.4 \%$ of the vegetated land areas, respectively. Meanwhile, the regions with changes toward drying conditions with confidence levels of very likely, likely, and probably cover $0.7 \%, 3.5 \%$, and $12.1 \%$, respectively. The remaining $45.0 \%$ of the vegetated-land areas studied have either no clear trends of drying or wetting or have conflicted trends. The drying trends are very likely to occur in the Paraguay River basin, the 


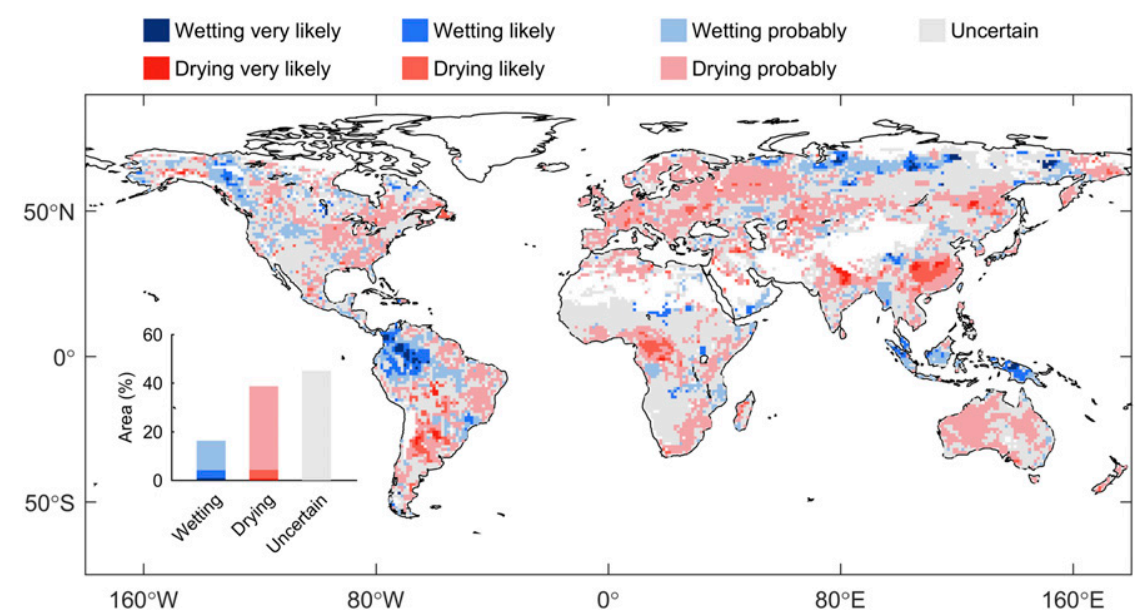

FIG. 2. Global pattern of wetting or drying trends over the period 1982-2012. The possibility of wetting or drying trends was observed through combining the variations of six drought indices. The inset shows the percentage area with consistent wetting or drying trends.

Pampas region of South America, and eastern and central Asia, while wetting trends are very likely to occur in the Amazon basin, the midwest of Siberia, and Southeast Asia.
To further downscale the spatial patterns of the dryness trends, we divided the global land surface into 26 zones as defined by IPCC (Fig. 3a). Wetting trends are observed in most parts of northern and central Europe,
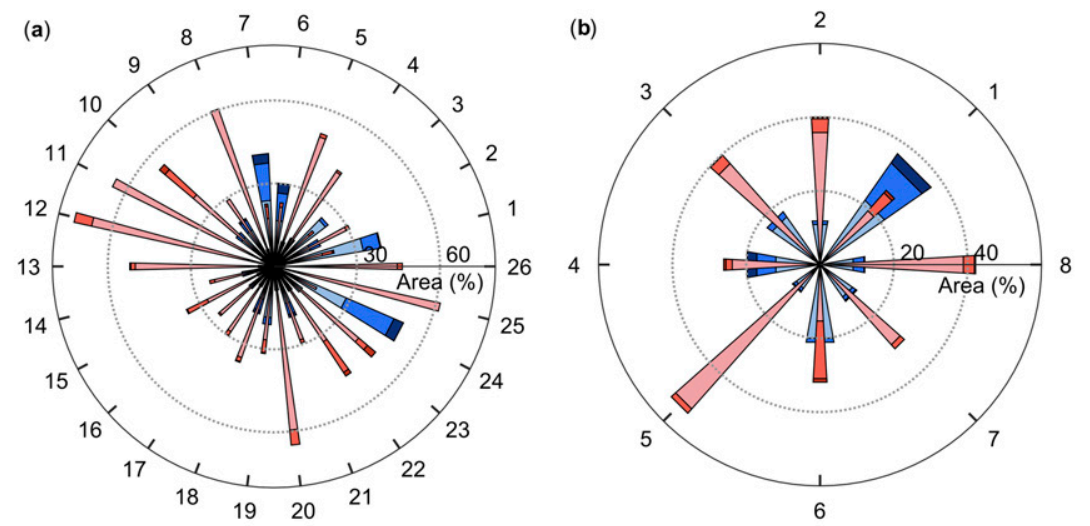

Wetting very likely $\quad$ Wetting likely $=$ Wetting probably Drying very likely

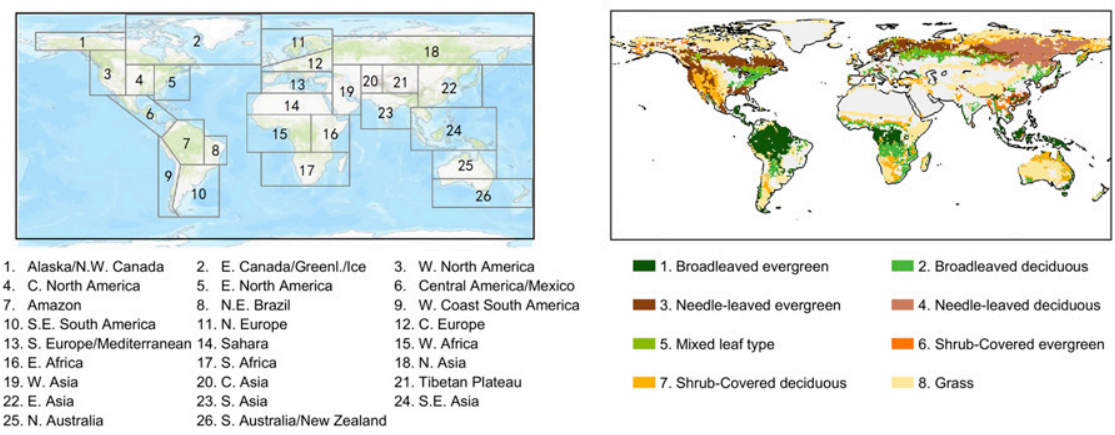

FIG. 3. Assessment of drying and wetting trends in (a) 26 regions and (b) eight biomes. The polar plots illustrate the percentage area with significant wetting or drying trends. The regional boundaries were derived from the IPCC Fifth Assessment Report (AR5). The distribution of biomes was obtained from the Global Land Cover 2000 Project (GLC 2000). 

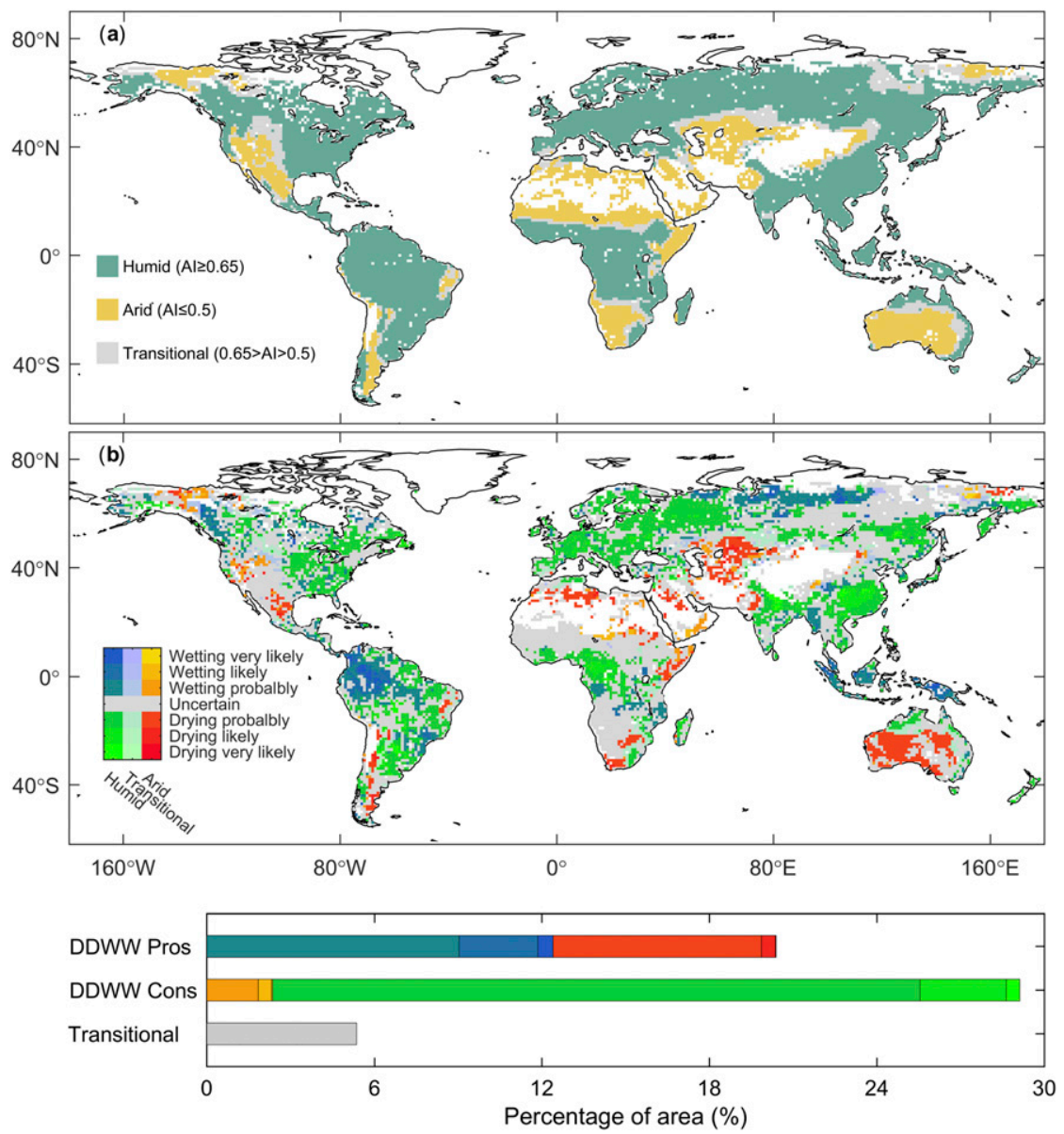

FIG. 4. Composite assessment of the DDWW paradigm based on multiple drought indices. (a) The distribution of arid, humid, and transitional areas classified according to the AI (the ratio between precipitation and PET) for the period 1982-2012. (b) Composite assessment map of the DDWW paradigm and percentage of area with significant change (not including uncertain areas). Pros or cons refer to evidence for or against the DDWW paradigm, respectively.

central Asia, Northeast Brazil, and Southeast Asia. A similar signal was observed in many parts of southeast South America, the Mediterranean, and South and East Asia. Wetting trends prevailed in Southeast Asia, the Amazon, and Alaska. In addition, we explored how the drying or wetting patterns varied by vegetation types (Fig. 3b) and found a general drying trend in the majority of shrub, grassland, and deciduous forest regions, except for the broadleaved evergreen forest biome, which was dominated by a wetting trend.

\section{c. Assessment of the DDWW paradigm}

To evaluate the validity of the DDWW paradigm over land, we classified regions by climate as arid, humid, or transitional using the commonly used AI. We found supporting evidence for the paradigm in circa $20.4 \%$ of the global land area. Some humid regions $(12.4 \%)$, such as the boreal regions, rain forest, and monsoon forest near the equator became wetter. The drought conditions in southwestern North America, North Africa, central Asia, and southern Australia tend to deteriorate (8.0\% area in total). We also identified about $29.1 \%$ of the global land area with the opposite pattern of the DDWW, that is, "dry gets wetter, and wet gets drier." Wet regions becoming drier, such as most parts of Europe, southeast China, east-central Africa, eastern North America, and central South America, made up $26.8 \%$ of the global vegetation-covered land area. On the other hand, arid regions that experienced a wetting trend only made up $2.4 \%$ of the global vegetationcovered land area. Transitional areas became wetter or drier in roughly equal proportions $(1.4 \%$ and $4.0 \%$ of global land area, respectively). The remaining $45.1 \%$ of land area experienced inconsistent or uncertain wetting or drying trends (Fig. 4). 


\section{Discussion}

\section{a. Drought indices show conflicted trends across the globe}

The six different drought indices used in this study showed conflicting wetting or drying trends. According to the driving forcing, our drought metrics could be categorized into a pure $P$-driven index (SPI), a pure ETdriven index (SETI), and mixed-driven indices (SPEI, AI, PDSI, and SSI). The $P$-driven index (SPI) shows that the wetting area is substantially larger than the drying area (Fig. 1; Figs. S1, S2). In parallel with the SPI, the AI and SPEI, two mixed-driven indices, also exhibit dominant wetting trends, especially in Africa, northern Asia, and the Amazon basin, and the drought area decreased significantly $(P<0.01)$ from 1982 to 2012 . Particularly, SPI and SPEI shared substantial similarities over the global trends during the period 1982-2012 and the spatial patterns of changes (Fig. 1; Figs. S1, S2). However, an increasing divergence in the trend between SPI and SPEI emerged during the latter part of the study period. The global-averaged trend slope of SPI is similar to that of SPEI during the period 1982-99 (Fig. S3), but becomes nearly 1.5 times as much as that of SPEI for the period 2000-12. Given that the only difference between these two indices lies in the consideration of $\mathrm{ET}_{0}$ in SPEI (Vicente-Serrano et al. 2010), these results suggest that the importance of $\mathrm{ET}_{0}$ might have increased in the latter period, which was a period of accelerated warming.

On the contrary to the $P$-driven index SPI and two mixed-driven indices SPEI and AI, SETI, an atmospheric dryness index driven by ET, reveals a widespread drying trend. This pattern is possibly due to the increases in evaporative losses in the form of soil evaporation and plant transpiration with higher air temperatures (Ding et al. 2018; Jung et al. 2010; Mu et al. 2007). Nevertheless, it does not necessarily mean an increasing drought and dryland expansion under global warming from the soil or hydrological moisture perspective, and indeed there is a significant increasing trend of water supply (precipitation) over global land surfaces (as indicated by SPI; Mao et al. 2015; Stagge et al. 2017; Swann and Koven 2017).

At the global scale, PDSI and SSI, the two mixeddriven indices with land surface conditions considered display little change of global dry area over the last three decades (Fig. 1). This result is consistent with the observed nonsignificant trend of Penman-Monteith (PM)based PDSI $\left(0.08 \% \pm 0.21 \% \mathrm{yr}^{-1}\right.$ during the period 1980-2008) reported by Sheffield et al. (2012) when using different combinations of precipitation and radiation datasets to generate an ensemble of sc_PDSI. The spatial pattern of the PDSI trend also differed substantially from those based on SPEI or AI (Fig. 1). This inconsistency could have stemmed from the inherent differences in the algorithms. Although both PDSI and SPEI use a balance between supply (precipitation) and demand of moisture in assessing drought severity, in SPEI a hypothetical measure of atmospheric evaporative demand, $\mathrm{ET}_{0}$ or PET, is used (Vicente-Serrano et al. 2010). In contrast, the basis of PDSI is a water-balance model in which actual evapotranspiration (the real flow of water from the surface to the atmosphere) is involved. Actual evapotranspiration could become decoupled from $\mathrm{ET}_{0}$ because of limited moisture availability (Anabalón and Sharma 2017). Furthermore, PDSI is less sensitive to variation in climate inputs than the SPEI, because of the use of the standardization procedure of water-balance anomalies in the PDSI algorithm (Vicente-Serrano et al. 2015). PDSI should be used cautiously in representing soil moisture drought based on global averages, because a small change in PDSI might be due to a great change in global runoff (Dai 2016).

In brief, the $P$-driven index (SPI) shows that the wetting area is substantially larger than the drying area. In contrast, the ET-driven index suggests that drying trends dominate most regions with significant changes in hydrological conditions (Fig. S4). When mixed-driven indices were used, the results show conflicted and indexspecific trends of either drying or wetting: SPEI and AI produce a dominant wetting trend, while PDSI and SSI, two indices with land surface conditions considered in the algorithm, produce a slight drying trend (Fig. S4). Collectively, both $P$ and ET, the two poles of drought forcing, have been strengthened in the climatic warming backgrounds, and the trends of hydrological changes over a specific region or at the global scale are ultimately dependent on which pole gained more emphasis, which is represented by the choices of index in the drought metric spectrum.

\section{b. A composite assessment indicates a prevailing drying trend}

Balancing the hydrological system is complex and involves multiple variables (Vicente-Serrano et al. 2012; Huntington 2006; Cook et al. 2014), such as precipitation (SPI), runoff (PDSI), soil moisture (SSI), and ET (SETI). These variables are represented differently (or not at all) by the different drought indices, subsequently, diverse patterns can be obtained when different indices are used, highlighting the fact that studies on changes in hydroclimate conditions cannot reliably depend on single dryness metrics. Integrated accounting of the various aspects of the surface moisture balance is therefore critical for alleviating the deficiencies 
associated with individual drought indices and providing increased confidence.

By integrating six commonly used drought indices, we quantitatively assessed the changes of hydrological conditions for the land surface in a spatially explicit way. Our composite analysis shows that drying trends occurred across much of the global vegetation-covered land (Fig. 2). Significant drying areas are more frequently encountered than wetting areas in most parts of 26 regions and eight biomes (Fig. 3). Both in wet and arid regions, drying areas are 2.4-3.3 times higher than wetting areas. This finding is consistent with the general expectation that a warming-induced increase in vaporpressure deficit and evaporative demand would lead to a drier future (Dai 2013; Huang et al. 2016). Climate change may exacerbate soil-water conditions over parts of the subtropical dry zone, for example, eastern China and southeastern South America, observed in this study (Fig. 2). Evidence for such changes has also been found in observations (Schlaepfer et al. 2017) and in climate model output (Wang 2005; Sheffield and Wood 2008). This was also evidenced by four three-index combinations from the drought metric spectrum to represent $P$-driven, $P$-ET-driven, and ET-driven indices (Fig. S5).

The wetting trend was particularly pronounced over the Northern Hemisphere high latitudes and northern South America (Figs. 2, 3). The observed polar-region wetting may very likely be ascribed to large-scale circulation changes, for example, expansion of the Hadley cell (Lu et al. 2007; Scheff and Frierson 2012) and a poleward shift in storm tracks contributing to poleward moistening (Scheff and Frierson 2012; Seager and Vecchi 2010). It may also be due to more moisture transport from high-latitude oceans to land because of an enhanced land-sea temperature contrast caused by the polar amplification of warming and warming over land being greater than that over the oceans (Byrne and O'Gorman 2015).

To further investigate the driving factor for the wetting or drying trends, we analyzed precipitation from multiple datasets, including CRU TS4.0, ERA-40, and GPCP, independently. Results based on these independent precipitation products suggested several clear and common patterns, such as significant increases in the Amazon basin, Southeast Asia, and northern North America and significant decreases in southern North America, eastern Asia, and southern Australia (Fig. S5). However, there were also disagreements between the observed trends in western and eastern North America when using different precipitation products. In arid and semiarid regions, for example, eastern Asia and North Africa, the discrepancy is larger than in relatively humid regions (Fig. S6). Collectively, these results indicate that precipitation may be the driving factor in relatively wet regions, while increasing temperature and concurrent evaporation increase may dominate the drying trends in these semiarid and arid regions (Dinku et al. 2011).

\section{c. A test of the DDWW paradigm}

The composite assessment results allow us to test the DDWW paradigm comprehensively. Our results reveal several large differences of wetting or drying trends compared with previous studies. For instance, Greve et al. (2014) found that only a quarter of the global land area experienced significant dryness or wetness changes, compared to the figure of $55 \%$ found in this study. They showed that the DDWW paradigm was valid for only $11 \%$ of the global vegetated land area. Our results, however, show that the paradigm holds for a larger fraction of the total land area $(20 \%)$. It is noteworthy that most previous assessments of DDWW were based on a single drought index, which may overemphasize a specific aspect of the water balance or suffer from indexspecific flaws. For example, from the perspective of water supply (precipitation), we found that the SPI trends largely lend support to the DDWW paradigm in many climate-sensitive regions. This also holds true for SPEI or AI, both mixed-driven metrics without consideration of land surface conditions. But for the $P$-ETdriven indices (PDSI, SSI) and the pure ET-driven metric (SETI), the supporting evidence for the paradigm was much less than that opposing the paradigm.

In this study, the integration of six commonly used drought indices ensures that various aspects of the water balance were taken into account, highlighting the overall hydroclimate conditions over the region of interest, instead of relying on any single dryness metric. Based on the updated set of drought metrics, the composite assessment map reveals that the DDWW theory was supported by $20 \%$ of land areas and was not supported by $29 \%$ of land areas. Another four three-index combinations representing $P$-driven, $P$-ET-driven, and ET-driven indices also reveal similar results (Fig. S5), implying that the DDWW paradigm is mainly useful for precipitation-driven regions and is less conclusive when multiple drought metrics are considered at the global scale.

Additionally, the composite assessment map illustrates an asymmetry in the DDWW paradigm as it shows a larger proportion of wet areas getting wetter than dry areas getting drier. Most wetland regions become wetter, especially in the high-latitude regions of the Northern Hemisphere and the Amazon basin, where robust wetting signals occurred during the past decades (Fig. S2). The fraction of dry areas becoming drier is smaller, but despite this, the signal is clear in many 
subtropical areas, such as central and southern Australia and western Asia, where it is possibly due to a combination of decreasing precipitation (Held and Soden 2006) and increasing atmospheric demand (Greve and Seneviratne 2015).

\section{Conclusions}

In this study, we clarified several issues regarding global vegetated-land moisture trends. First, we confirmed that different drought indices, which inherently place different emphases on various aspects of the water balance, tend to produce apparently contradictory results when tested on consistent datasets. Instead of using a single drought index, we integrated six drought indices into a composite map of global dryness or wetness trends and found the majority $(55 \%)$ of land area experienced wetting or drying trends. Other regions were found to have nonsignificant or conflicting trends. Significant changes toward drier conditions dominated over much of the global land area (38\%). Furthermore, we believe that the long-standing debate on DDWW could be reconciled by the nature of drought metrics used, either with emphasis on $P$ or ET or with land surface conditions considered. The DDWW theory is more useful when the $P$-driven drought metrics are considered, but when drought metrics that integrate ET and soil conditions are used, the DDWW is not conclusive.

Acknowledgments. This study was supported by the National Natural Science Foundation of China (41530528, 41871104), Key Research and Development Programs for Global Change and Adaptation (Grant 2017YFA0603604), the Strategic Priority Research Program (A) of the Chinese Academy of Sciences (Grant XDA20050101), International Partnership Program of the Chinese Academy of Sciences (Grant 131C11KYSB20160061), the 13th Five-Year Informatization Plan of Chinese Academy of Sciences (Grant XXH13505-06), the Thousand Youth Talents Plan project in China, the General Financial Grant from the China Postdoctoral Science Foundation (2017M620922), and KCRE (Kathmandu Center for Research and Education, CAS-TU) support in Nepal.

\section{REFERENCES}

Allen, R. G., L. S. Pereira, D. Raes, and M. Smith, 1998: Crop evapotranspiration-Guidelines for computing crop water requirements. FAO Rep. 56, 15 pp., https://appgeodb.nancy.inra.fr/ biljou/pdf/Allen_FAO1998.pdf.

Alley, W. M., 1984: The Palmer drought severity index: Limitations and assumptions. J. Climate Appl. Meteor., 23, 1100-1109,
https://doi.org/10.1175/1520-0450(1984)023<1100:TPDSIL> 2.0.CO;2.

Anabalón, A., and A. Sharma, 2017: On the divergence of potential and actual evapotranspiration trends: An assessment across alternate global datasets. Earth's Future, 5, 905-917, https:// doi.org/10.1002/2016EF000499.

Berg, A., and J. Sheffield, 2018: Climate change and drought: The soil moisture perspective. Curr. Climate Change Rep., 4, 180191, https://doi.org/10.1007/s40641-018-0095-0.

Briffa, K. R., G. van der Schrier, and P. D. Jones, 2009: Wet and dry summers in Europe since 1750: Evidence of increasing drought. Int. J. Climatol., 29, 1894-1905, https://doi.org/10.1002/ joc. 1836 .

Burke, E. J., and S. J. Brown, 2008: Evaluating uncertainties in the projection of future drought. J. Hydrometeor., 9, 292-299, https://doi.org/10.1175/2007JHM929.1.

Byrne, M. P., and P. A. O'Gorman, 2015: The response of precipitation minus evapotranspiration to climate warming: Why the "wet-get-wetter, dry-get-drier" scaling does not hold over land. J. Climate, 28, 8078-8092, https://doi.org/10.1175/ JCLI-D-15-0369.1.

Chou, C., J. D. Neelin, C.-A. Chen, and J.-Y. Tu, 2009: Evaluating the "rich-get-richer" mechanism in tropical precipitation change under global warming. J. Climate, 22, 1982-2005, https:// doi.org/10.1175/2008JCLI2471.1.

Cook, B. I., J. E. Smerdon, R. Seager, and S. Coats, 2014: Global warming and 21st century drying. Climate Dyn., 43, 2607-2627, https://doi.org/10.1007/s00382-014-2075-y.

Dai, A., 2011: Drought under global warming: A review. Wiley Interdiscip. Rev.: Climate Change, 2, 45-65, https://doi.org/ 10.1002/wcc.81; Corrigendum, 3, 617, https://doi.org/10.1002/ wcc. 190 .

_ 2013: Increasing drought under global warming in observations and models. Nat. Climate Change, 3, 52-58, https:// doi.org/10.1038/nclimate1633; Corrigendum, 3, 171, https:// doi.org/10.1038/nclimate1811.

_ 2016: Historical and future changes in streamflow and continental runoff. Terrestrial Water Cycle and Climate Change, Geophys. Monogr., Vol. 221, Amer. Geophys. Union, 17-37, https://doi.org/10.1002/9781118971772.ch2.

— K. E. Trenberth, and T. Qian, 2004: A global data set of Palmer drought severity index for 1870-2002: Relationship with soil moisture and effects of surface warming. J. Hydrometeor., 5, 1117-1130, https://doi.org/10.1175/JHM-386.1.

Ding, J., and Coauthors, 2018: Increasingly important role of atmospheric aridity on Tibetan alpine grasslands. Geophys. Res. Lett., 45, 2852-2859, https://doi.org/10.1002/2017GL076803.

Dinku, T., P. Ceccato, and S. J. Connor, 2011: Challenges of satellite rainfall estimation over mountainous and arid parts of East Africa. Int. J. Remote Sens., 32, 5965-5979, https://doi.org/ 10.1080/01431161.2010.499381.

Farahmand, A., and A. Aghakouchak, 2015: A generalized framework for deriving nonparametric standardized drought indicators. Adv. Water Resour., 76, 140-145, https://doi.org/ 10.1016/j.advwatres.2014.11.012.

Feng, H., and M. Zhang, 2015: Global land moisture trends: Drier in dry and wetter in wet over land. Sci. Rep., 5, 18018, https:// doi.org/10.1038/srep18018.

Feng, S., and Q. Fu, 2013: Expansion of global drylands under a warming climate. Atmos. Chem. Phys., 13, $10081-10094$, https:// doi.org/10.5194/acp-13-10081-2013.

Gilbert, R. O., 1988: Statistical Methods for Environmental Pollution Monitoring. Van Nostrand Reinhold Co., 336 pp. 
Greve, P., and S. I. Seneviratne, 2015: Assessment of future changes in water availability and aridity. Geophys. Res. Lett., 42, 54935499, https://doi.org/10.1002/2015GL064127.

- B. Orlowsky, B. Mueller, J. Sheffield, M. Reichstein, and S. I. Seneviratne, 2014: Global assessment of trends in wetting and drying over land. Nat. Geosci., 7, 716-721, https://doi.org/ 10.1038/ngeo2247; Corrigendum, 7, 848, https://doi.org/10.1038/ ngeo2274.

Held, I. M., and B. J. Soden, 2006: Robust responses of the hydrological cycle to global warming. J. Climate, 19, 5686-5699, https://doi.org/10.1175/JCLI3990.1; Corrigendum, 24, 1559-1560, https://doi.org/10.1175/2010JCLI4045.1.

Hoekstra, A. Y., and M. M. Mekonnen, 2012: The water footprint of humanity. Proc. Natl. Acad. Sci. USA, 109, 3232-3237, https:// doi.org/10.1073/pnas.1109936109.

Huang, J., M. Ji, Y. Xie, S. Wang, Y. He, and J. Ran, 2016: Global semi-arid climate change over last 60 years. Climate Dyn., 46, 1131-1150, https://doi.org/10.1007/s00382-015-2636-8.

Hulme, M., R. Marsh, and P. D. Jones, 1992: Global changes in a humidity index between 1931-60 and 1961-90. Climate Res., 2 , 1-22, https://doi.org/10.3354/cr002001.

Huntington, T. G., 2006: Evidence for intensification of the global water cycle: Review and synthesis. J. Hydrol., 319, 83-95, https:// doi.org/10.1016/j.jhydrol.2005.07.003.

Jensen, M. E., R. D. Burman, and R. G. Allen, 1990: Evapotranspiration and Irrigation Water Requirements: A manual. American Society of Civil Engineers, 332 pp., https://doi.org/ $10.1061 / 9780784414057$.

Jung, M., and Coauthors, 2010: Recent decline in the global land evapotranspiration trend due to limited moisture supply. Nature, 467, 951-954, https://doi.org/10.1038/nature09396.

Kendall, M. G., 1975: Rank Correlation Methods. 4th ed. Charles Griffin, 202 pp.

Kumar, S., R. P. Allan, F. Zwiers, D. M. Lawrence, and P. A. Dirmeyer, 2015: Revisiting trends in wetness and dryness in the presence of internal climate variability and water limitations over land. Geophys. Res. Lett., 42, $10867-10$ 875, https:// doi.org/10.1002/2015GL066858.

Liu, C., and R. P. Allan, 2013: Observed and simulated precipitation responses in wet and dry regions 1850-2100. Environ. Res. Lett., 8, 034002, http://iopscience.iop.org/1748-9326/8/3/034002.

Lu, J., G. A. Vecchi, and T. Reichler, 2007: Expansion of the Hadley cell under global warming. Geophys. Res. Lett., 34, L06805, https://doi.org/10.1029/2006GL028443; Corrigendum, 34, L14808, https://doi.org/10.1029/2007GL030931.

- - D. Xue, Y. Gao, G. Chen, L. R. Leung, and P. Staten, 2018: Enhanced hydrological extremes in the western United States under global warming through the lens of water vapor wave activity. Climate Atmos. Sci., 1, 7, https://doi.org/10.1038/ s41612-017-0007-3.

Mann, H. B., 1945: Nonparametric tests against trend. Econometrica, 13, 245-259, https://doi.org/10.2307/1907187.

Mao, J., and Coauthors, 2015: Disentangling climatic and anthropogenic controls on global terrestrial evapotranspiration trends. Environ. Res. Lett., 10, 094008, http://iopscience.iop.org/ article/10.1088/1748-9326/10/9/094008.

Martens, B., and Coauthors, 2017: Gleam v3: Satellite-based land evaporation and root-zone soil moisture. Geosci. Model Dev. 10, 1903-1925, https://doi.org/10.5194/gmd-10-1903-2017.

McKee, T. B., N. J. Doesken, and J. Kleist, 1993: The relationship of drought frequency and duration to time scales. Preprints, Eighth Conf. on Applied Climatology, Anaheim, CA, Amer. Meteor. Soc., 179-184.
Miralles, D. G., R. A. M. de Jeu, J. H. Gash, T. R. H. Holmes, and A. J. Dolman, 2011: Magnitude and variability of land evaporation and its components at the global scale. Hydrol. Earth Syst. Sci., 15, 967-981, https://doi.org/10.5194/hess-15-967-2011.

Mishra, A. K., and V. P. Singh, 2011: Drought modeling-A review. J. Hydrometeor., 403, 157-175, https://doi.org/10.1016/ j.jhydrol.2011.03.049.

Mu, Q., F. A. Heinsch, M. Zhao, and S. W. Running, 2007: Development of a global evapotranspiration algorithm based on MODIS and global meteorology data. Remote Sens. Environ., 111, 519-536, https://doi.org/10.1016/j.rse.2007.04.015.

Palmer, W., 1965: Meteorological drought. U.S. Weather Bureau Research Paper 45, 65 pp., https://www.ncdc.noaa.gov/temp-andprecip/drought/docs/palmer.pdf.

Peñuelas, J., and Coauthors, 2017: Assessment of the impacts of climate change on Mediterranean terrestrial ecosystems based on data from field experiments and long-term monitored field gradients in Catalonia. Environ. Exp. Bot., 152, 49-59, https:// doi.org/10.1016/j.envexpbot.2017.05.012.

Piao, S., and Coauthors, 2010: The impacts of climate change on water resources and agriculture in China. Nature, 467, 43-51, https://doi.org/10.1038/nature09364.

Quiring, S. M., and S. Ganesh, 2010: Evaluating the utility of the Vegetation Condition Index (VCI) for monitoring meteorological drought in Texas. Agric. For. Meteor., 150,330-339, https:// doi.org/10.1016/j.agrformet.2009.11.015.

Reichle, R. H., R. D. Koster, J. Dong, and A. A. Berg, 2004: Global soil moisture from satellite observations, land surface models, and ground data: Implications for data assimilation. J. Hydrometeor., 5, 430-442, https://doi.org/10.1175/ 1525-7541(2004)005<0430:GSMFSO > 2.0.CO;2.

Scheff, J., and D. M. W. Frierson, 2012: Robust future precipitation declines in CMIP5 largely reflect the poleward expansion of model subtropical dry zones. Geophys. Res. Lett., 39, L18704, https://doi.org/10.1029/2012GL052910.

Schlaepfer, D. R., and Coauthors, 2017: Climate change reduces extent of temperate drylands and intensifies drought in deep soils. Nat. Commun., 8, 14196, https://doi.org/10.1038/ ncomms14196.

Seager, R., and G. A. Vecchi, 2010: Greenhouse warming and the 21st century hydroclimate of southwestern North America. Proc. Natl. Acad. Sci. USA, 107, 21 277-21 282, https://doi.org/ 10.1073/pnas.0910856107.

Seneviratne, S. I., T. Corti, E. L. Davin, M. Hirschi, E.B. Jaeger, I. Lehner, B. Orlowsky, and A. J. Teuling, 2010: Investigating soil moisture-climate interactions in a changing climate: A review. Earth-Sci. Rev., 99, 125-161, https://doi.org/10.1016/ j.earscirev.2010.02.004.

Sheffield, J., and E. F. Wood, 2008: Projected changes in drought occurrence under future global warming from multi-model, multi-scenario, IPCC AR4 simulations. Climate Dyn., 31, 79105, https://doi.org/10.1007/s00382-007-0340-z.

G. Goteti, F. Wen, and E. F. Wood, 2004: A simulated soil moisture based drought analysis for the United States. J. Geophys. Res., 109, D24108, https://doi.org/10.1029/ 2004JD005182.

_ E. F. Wood, and M. L. Roderick, 2012: Little change in global drought over the past 60 years. Nature, 491, 435-438, https:// doi.org/10.1038/nature11575.

Stagge, J. H., D. G. Kingston, L. M. Tallaksen, and D. M. Hannah, 2017: Observed drought indices show increasing divergence across Europe. Sci. Rep., 7, 14045, https://doi.org/10.1038/ s41598-017-14283-2. 
Swann, A. L. S., and C. D. Koven, 2017: A direct estimate of the seasonal cycle of evapotranspiration over the Amazon basin. J. Hydrometeor., 18, 2173-2185, https://doi.org/10.1175/JHM-D-17-0004.1.

, F. M. Hoffman, C. D. Koven, and J. T. Randerson, 2016: Plant responses to increasing $\mathrm{CO}_{2}$ reduce estimates of climate impacts on drought severity. Proc. Natl. Acad. Sci. USA, 113, 10 019-10 0024, https://doi.org/10.1073/pnas.1604581113.

Thornton, P. K., P. J. Ericksen, M. Herrero, and A. J. Challinor, 2014: Climate variability and vulnerability to climate change: A review. Global Change Biol., 20, 3313-3328, https://doi.org/ 10.1111/gcb.12581.

Trenberth, K. E., A. Dai, G. van der Schrier, P. D. Jones, J. Barichivich, K. R. Briffa, and J. Sheffield, 2014: Global warming and changes in drought. Nat. Climate Change, 4, 1722, https://doi.org/10.1038/nclimate2067.

UNEP, 1992: World Atlas of Desertification. Edward Arnold, 69 pp.

Vicente-Serrano, S. M., 2006: Differences in spatial patterns of drought on different time scales: An analysis of the Iberian Peninsula. Water Resour. Manage., 20, 37-60, https://doi.org/ 10.1007/s11269-006-2974-8.

_, S. Beguería, and J. I. López-Moreno, 2010: A multiscalar drought index sensitive to global warming: The standardized precipitation evapotranspiration index. J. Climate, 23, 16961718, https://doi.org/10.1175/2009JCLI2909.1.
_ - and Coauthors, 2012: Performance of drought indices for ecological, agricultural, and hydrological applications. Earth Interact., 16, https://doi.org/10.1175/2012EI000434.1.

_- , G. Van der Schrier, S. Beguería, C. Azorin-Molina, and J.-I. Lopez-Moreno, 2015: Contribution of precipitation and reference evapotranspiration to drought indices under different climates. J. Hydrol., 526, 42-54, https://doi.org/10.1016/ j.jhydrol.2014.11.025.

Wang, G., 2005: Agricultural drought in a future climate: Results from 15 global climate models participating in the IPCC 4th assessment. Climate Dyn., 25, 739-753, https://doi.org/10.1007/ s00382-005-0057-9.

Wang, X., T. Wang, D. Liu, H. Guo, H. Huang, and Y. Zhao, 2017: Moisture-induced greening of the South Asia over the past three decades. Global Change Biol., 23, 4995-5005, https:// doi.org/10.1111/gcb.13762.

Yilmaz, M. T., W. T. Crow, and D. Ryu, 2016: Impact of model relative accuracy in framework of rescaling observations in hydrological data assimilation studies. J. Hydrometeor., 17, 2245-2257, https://doi.org/10.1175/JHM-D-15-0206.1.

Zhao, T., and A. Dai, 2015: The magnitude and causes of global drought changes in the twenty-first century under a lowmoderate emissions scenario. J. Climate, 28, 4490-4512, https:// doi.org/10.1175/JCLI-D-14-00363.1. 